\title{
Validation of Cryogenic Vacuum Extraction of Pore Water from Volcanic Soils for Isotopic Analysis
}

\author{
Diego Rivera ${ }^{1,2, *} \mathbb{C}$, Karen Gutierrez ${ }^{2}$, Walter Valdivia-Cea ${ }^{2}$, Mauricio Zambrano-Bigiarini $\left.{ }^{3,4}{ }^{(}\right)$, \\ Alex Godoy-Faúndez ${ }^{5}$ (i) , Amaya Álvez ${ }^{1}$ and Laura Farías ${ }^{4,6}$ \\ 1 Centro de Recursos Hídricos para la Agricultura y la Minería, CONICYT/FONDAP 15130015, \\ Chillán 3812120, Chile \\ 2 Department of Water Resources, Laboratory of Comparative Policy in Water Resources Management, \\ Universidad de Concepción, Chillán 3812120, Chile; kargutierrez@udec.cl (K.G.); \\ waltervaldivia@udec.cl (W.V.-C.) \\ 3 Department of Civil Engineering, Universidad de La Frontera, Temuco 4780000, Chile; \\ mauricio.zambrano@ufrontera.cl \\ 4 Center for Climate and Resilience Research (CR)2, CONICYT/FONDAP 15110009, \\ Concepción 4070386, Chile; laura.farias@udec.cl \\ 5 Centro de Investigación en Sustentabilidad y Gestión Estratégica de Recursos, Facultad de Ingeniería, \\ Universidad del Desarrollo, Santiago 7610658, Chile; alexgodoy@ingenieros.udd.cl \\ 6 Department of Oceanography, Universidad de Concepción, Concepción 4070386, Chile \\ * Correspondence: dirivera@udec.cl; Tel.: +56-9799-97922
}

Received: 10 September 2019; Accepted: 22 October 2019; Published: 24 October 2019

\begin{abstract}
Andean headwater catchments are key components of the hydrological cycle, given that they capture moisture, store water and release it for Chilean cities, industry, agriculture, and cities in Chile. However, knowledge about within-Andean catchment processes is far from clear. Most soils in the Andes derive from volcanic ash Andosols and Arenosols presenting high organic matter, high-water retention capacity and fine pores; and are very dry during summer. Despite their importance, there is little research on the hillslope hydrology of Andosols. Environmental isotopes such as Deuterium and 18-O are direct tracers for water and useful on analyzing water-soil interactions. This work explores, for the first time, the efficiency of cryogenic vacuum extraction to remove water from two contrasting soil types (Arenosols, Andosols) at five soil water retention energies (from -1500 to $-33 \mathrm{kPa}$ ). Two experiments were carried out to analyse the impact of extraction time, and initial water content on the amount of extracted water, while a third experiment tested whether the cryogenic vacuum extraction changed the isotopic ratios after extraction. Minimum extraction times to recover over $90 \%$ of water initially in the soil samples were $40-50$ min and varied with soil texture. Minimum volume for very dry soils were $0.2 \mathrm{~mL}$ (loamy sand) and $1 \mathrm{~mL}$ (loam). After extraction, the difference between the isotope standard and the isotopic values after extraction was acceptable. Thus, we recommend this procedure for soils derived from volcanic ashes.
\end{abstract}

Keywords: cryogenic vacuum extraction; volcanic soils; isotopic analysis

\section{Introduction}

Natural isotopes such as ${ }^{18} \mathrm{O}$ and ${ }^{2} \mathrm{H}$ are direct tracers for water cycles, allowing to identify the origin, recharge and evolution of surface waters and groundwater [1]. Thus, natural isotopes on pore water are widely used in hillslope hydrology to investigate subsurface paths, infiltration, mixing processes and runoff generation, across different spatio-temporal scales [2-9], as water's isotopic ratios $\left({ }^{18} \mathrm{O} /{ }^{16} \mathrm{O}\right.$ or $\left.{ }^{2} \mathrm{H} /{ }^{1} \mathrm{H}\right)$ changes while passing from one phase to another. For instance, during evaporation and transpiration, there is an enrichment of heavier isotopes [1]. In ecohydrology, 
natural isotopes are used to analyze pore-water in the soil, i.e., mobile water or water on finer pores, under water uptake by vegetation and different soil drying dynamics, to differentiate water sources such as groundwater or precipitation [10-13].

There is a plethora of methods to extract water from soil pores, from mechanical procedures, such as centrifugation, to methods that involve water phase change and subsequent recovery of water vapor, such as vapor equilibrium and cryogenic vacuum extraction. Di Bonito et al. [14], Millar et al. [15] and Orlowski et al. [16] give detailed assessments and comparison of methods. Among these listed techniques, cryogenic vacuum extraction (CVE) is widely used due to its easy setup and operation [17-19]. In this procedure, soil (or other material) is heated $\left(>90^{\circ} \mathrm{C}\right)$ under vacuum. Then, water evaporated from the soil is subsequently caught in a cold trap, generally liquid Nitrogen, also under vacuum. After defrosting, the liquid water sample is accessible for isotope analysis [20]. The equipment to perform cryogenic distillation varies from multi-port systems, providing the possibility to extract simultaneously a larger number of samples per day [18], to less expensive systems such as the one described in [17], consisting in two tubes joint by a steel capillary. However, there are no standards to assemble and operate cryogenic vacuum extraction devices, so extraction lines must be carefully setup in terms of its components and its proficiency depends on soil type, plant type and water content $[20,21]$. These variables define the sample amount and extraction times needed to recover most of pore water in the sample [22,23]. Regarding soil-related variables affecting CVE performance, high clay content, as well as low soil water content on samples, could contribute to significant differences between the isotopic signatures of recovered water and pore water $[21,23]$.

Depending on the pedological development, volcanic soils can present high clay content Andosols or high sand content Arenosols that are both part of the same pedological (hillslope) units with high organic matter content (7-12\%) and high water retention capacity due to the development of interand intra-aggregate voids [24-28]. Moreover, soils attain very low water content during the austral spring and summer (October to March). Thus, soils from volcanic ashes in upper Andean catchments present physical properties that could affect the efficiency of CVE. In this regard [13] used CVE in well-developed Andosols, but to our knowledge, this work is the first to explore two contrasting soil types: Arenosols and Andosols, at five soil water retention energies. Even though the literature reports success on extracting water from sandy soils using centrifugation [14,16] or suction cups [20], it is worth noting that it was not possible to extract water from our samples using the cited methods due to their volcanic nature of soils, either at wet or dry moisture levels.

We investigated the proficiency of cryogenic vacuum extraction of pore-water in two soils derived from volcanic ashes from the Andes mountains, due to their unique physical such as high clay content, high water retention capacity and finer pores. We present the results for pore-water by cryogenic extraction in two different soils derived from volcanic ashes. We employed the set-up for cryogenic vacuum extraction lines described by Koeniger et al. [17], considering previously reported critical issues in cryogenic extraction, such as time of extraction, initial water content and volume of pore water extracted from soil [20-23].

\section{Materials and Methods}

We tested the time to extract a significant percentage of water in the soil sample (over $90 \%$ ) for five water content levels, from very wet $(33 \mathrm{kPa})$ to very dry $(1300 \mathrm{kPa})$. Also, we tested whether the volume of the extracted water from soil is viable for laboratory analysis and whether there are changes on the isotopic ratios after water passed through the extraction line.

Two large soil samples (ca., $2 \mathrm{~kg}$ each) were collected at $3200 \mathrm{~m}$ a.s.l. from two trenches on Arenosols and Andosols within a single site located in an upper catchment of the Itata River Basin $\left(33^{\circ}-38^{\circ} \mathrm{S}\right.$, Figure 1$)$. The Itata watershed is rainfall-dominated, with a small glacier area that melts from September to January and several small lakes in moraines and glacial cirques. 

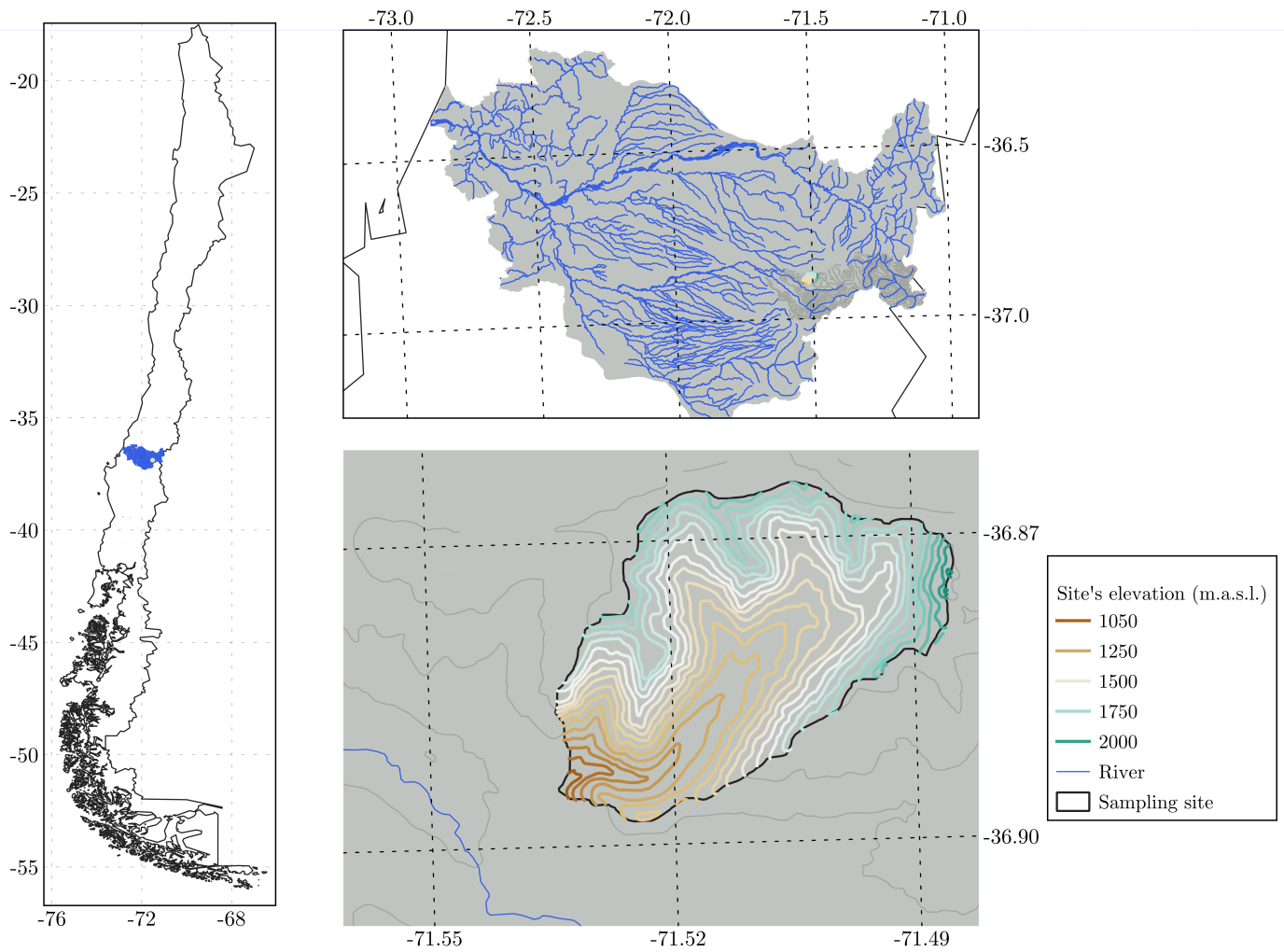

Figure 1. Location of the study site.

Additionally, we processed over 60 soil samples from the site, taken at different depths during the (dry and hot) summer season, in order to test whether the isotopic ratios of extracted water show changes due to water evaporation from soil. This was done according to other field studies [5-9].

\subsection{Soil Samples}

Soil samples were placed in plastic bags for transportation to the laboratory. Then, samples were oven-dried for $24 \mathrm{~h}$ at $105{ }^{\circ} \mathrm{C}$ and kept refrigerated for further use. Parts of the samples were used for physical analyses, such as sand, clay and silt content, bulk density, and water content at five retention energies. Due to the site's Mediterranean climate, soils are very dry during summer, close to permanent wilting point. For that reason, we tested the extraction device for different retention energies $(-33,-100,-300,-500$ and $-1500 \mathrm{kPa})$ by fitting a water retention curve [29].

Table 1 presents the physical characteristics of loamy-sand and loam soils, which are representative of the site. Arenosols are young ash soils, with low clay content (70-80\% sand and $20-25 \%$ silt), while Andosols are clayey, older ash soils (over 40\% clay) [28]. Andosols show a higher total pore volume and a higher field capacity than Arenosols, mainly due to a higher volume of fine pores [28]. Thus, loamy-sand soil was classified as Arenosols and Loam soil was classified as Andosols.

Calculations show that there is a large difference in the amount of water in soil samples, depending on the soil classification. By using data on Table 1, $10 \mathrm{~g}$ of Arenosols at field capacity contains ca., $0.6 \mathrm{~g}$ of water, while $10 \mathrm{~g}$ of Andosols at field capacity contains ca., $4 \mathrm{~g}$ of water. On the other hand, in $10 \mathrm{~g}$ of dry soil (retention energy of $-1500 \mathrm{kPa}$ ), there will be ca., $0.3 \mathrm{~g}$ of water for Arenosols and $2.5 \mathrm{~g}$ in the case of Andosols. 
Table 1. Physical soil properties following the procedures described in [29]. Water content is given as percentage of dry weight.

\begin{tabular}{ccc}
\hline Physical Property & Arenosols & Andosols \\
\hline USDA Classification & Loamy-sand & Loam \\
Sand content $(\%)$ & 84.9 & 36.9 \\
Clay content $(\%)$ & 9.3 & 49.7 \\
Silt content $(\%)$ & 5.8 & 13.9 \\
Bulk density $\left(\mathrm{kg} / \mathrm{m}^{3}\right)$ & 1.31 & 1.28 \\
Water content at $-33 \mathrm{kPa}(\%)$, Field Capacity & 6.54 & 48.9 \\
Water content at $-100 \mathrm{kPa}(\%)$ & 5.48 & 41.0 \\
Water content at $-300 \mathrm{kPa}(\%)$ & 4.60 & 36.0 \\
Water content at -500 kPa (\%) & 4.2 & 32.2 \\
Water content at - $1500 \mathrm{kPa}(\%)$, Permanent Wilting Point & 3.57 & 26.9 \\
\hline
\end{tabular}

\subsection{Extraction Procedure}

Cryogenic vacuum extraction extracts water from wet soil samples by means of a cold trap for water vapor. We set up seven extraction lines following the instructions given in Koeniger et al. [17]. Soil samples were placed in a $10 \mathrm{~mL}$ Vacutainer with plastic-silicon septa, and linked to another Vacutainer by a stainless tube of $1.56 \times 0.96 \mathrm{~mm}$. The stainless tube had attached a needle at both ends. Vacuum conditions ( -0.85 to -0.9 bar) were attained by a vacuum pump (VacuPorte, UMS AG, USA) (Figure 2a). The tube containing the soil sample was placed in an isothermal bath filled with water at $90{ }^{\circ} \mathrm{C}$, while the receiving tube was placed in liquid Nitrogen. Thus, water evaporated from the soil material was subsequently caught in the cold trap [23] (Figure 2b-d). This device allows seven simultaneous extraction runs (Figure 2e).

We used conventional notation for stable isotope composition: $\delta^{18} \mathrm{O}$ or $\delta^{2} \mathrm{H}$ is the ratio Rsample/RVSMOW; where $\mathrm{R}$ is the ratio ${ }^{18} \mathrm{O} /{ }^{16} \mathrm{O}$ or ${ }^{2} \mathrm{H} /{ }^{1} \mathrm{H}$ relative to the Vienna Standard Mean Ocean Water (VSMOW). Extracted pore water after cryogenic extraction went to isotopic analysis using a Picarro L2130-i Isotope and Gas Concentration Analyzer (Picarro, Santa Clara, USA). Precision for liquid samples was guaranteed to be $-0.025 \%$ and $0.1 \%$ for $\delta^{18}$ and $\delta^{2} \mathrm{H}$, respectively.

To test the efficiency of CVE on volcanic soils, we ran three experiments (Table 2). Experiment A assessed the effect of extraction time on the volume of recovered water from soil samples (Andosols and Arenosols) at field capacity, while varying the extraction times from 10 to $50 \mathrm{~min}$. Experiment B assessed the effect of initial water content on the volume of recovered water, as drier soil samples contain less water and pore-water is retained at higher energies, while fixing the extraction time to $50 \mathrm{~min}$. In experiments A and B, by using the water retention curve, it was possible to calculate the mass of deionized water to re-hydrate the soil samples to the desired level. After each run, soil was dried again to calculate the amount of remaining water in the sample. Experiment $C$ was set to check whether the procedure significantly changed the isotopic ratio of pore-water spiked with a reference water of known isotopic composition. Samples of $10 \mathrm{~g}$ of soil were re-hydrated to saturation with $4 \mathrm{~g}$ of labelled water and then refrigerated for $24 \mathrm{~h}$ following Orlowski et al. [23]. Labelled water was provided by the Comisión Chilena de Energía Nuclear (National Commission for Nuclear Energy) for blind comparison. 


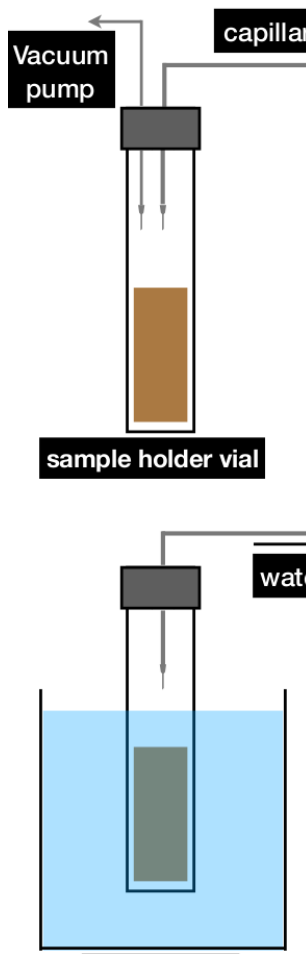

Water bath (a)

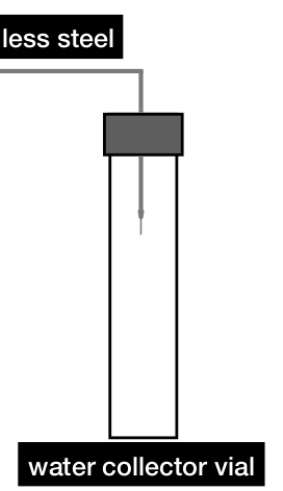

(c)

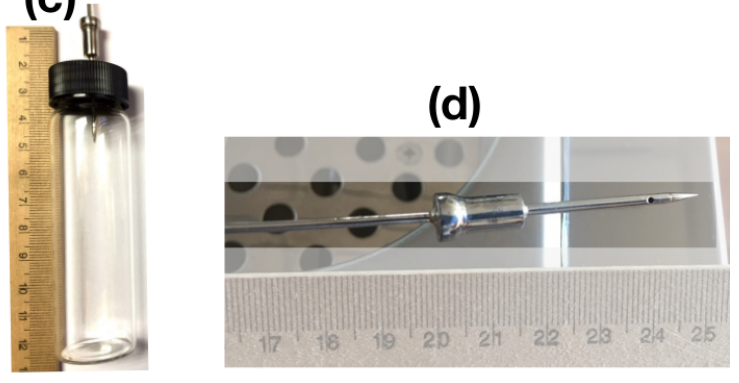

Figure 2. (a) Schematics for sample preparation (b) Schematics for cryogenic vacuum extraction (c) Detail of Vacutainer with screw cap and silicon septa (d) Detail of needles attached to stainless steel capillaries (e) Cryogenic extraction setup.

Table 2. Description of experiments A, B and C.

\begin{tabular}{cccc}
\hline Description & Experiment A & Experiment B & Experiment C \\
\hline Soil & Arenosols $(\mathrm{n}=12)$ & Arenosols $(\mathrm{n}=15)$ & Arenosols $(\mathrm{n}=2)$ \\
& Andosols $(\mathrm{n}=12)$ & Andosols $(\mathrm{n}=15)$ & Andosols $(\mathrm{n}=2)$ \\
Pore water tension $(|\Psi|, \mathrm{kPa})$ & 33 & $33,100,300,500,1500$ & saturation \\
Extraction time $(\mathrm{min})$ & $10,25,40,50$ & 50 & 50 \\
Soil sample weight $(\mathrm{g})$ & 10.34 & 10.34 & 10 \\
\hline
\end{tabular}

\section{Results}

Experimental results are shown in terms of two relevant variables for equipment operation: the volume of extracted water $(\mathrm{mL})$ and extraction time (minutes). In addition, to assess the efficiency of the extraction procedure we present the ratio of extracted water to the total amount of water in the soil samples prior to the cryogenic vacuum extraction.

Results from Experiment A answer one of the main operational questions, that is, whether the amount of recovered water is enough to run stable isotopes analysis (Table 3, Figure 3a). For both soils, it was possible to recover after 50 min over $0.6 \mathrm{~g}$ of water for Arenosols and over $2.6 \mathrm{~g}$ for Andosols, starting from a water content close to saturation. Differences on the mass of recovered water for both soil types was due to different amounts of water that were added to the soil samples for re-hydration to attain field capacity. In the case of loamy-sand samples, the amount of water added was low, ca., $0.7 \mathrm{~g}$, because that soil type exhibits a low water retention capacity (approximately $5 \%$ of dry weight). In the case of loamy soil, higher clay content led to higher water retention capacity (approximately $25 \%$ in dry weight basis), so there was more water pore on soil samples. Thus, in both cases, extraction times over 50 min could recover enough water mass per sample to be processed with the laboratory equipment. 
After $50 \mathrm{~min}$ it was possible to recover over $90 \%$ of pore water for both soils, calculated as the ratio of the volume of pore water in the sample to water recovered (Recovery $(\%)=\mathrm{PW} / \mathrm{EW}$ in Table 3). However, there is a difference on the recovery percentage between Arenosols ( $94 \%$ after $50 \mathrm{~min}$ ) and Andosols (91\% after $50 \mathrm{~min}$ ). For loamy-sand samples Arenosols, all values of recovery percentages after different extraction times were statistically different from each other, while there were significant differences on the volume of extracted water as extraction time for loam soil -Andosols- increases from 25 to 40 min (two-way ANOVA test, $p$-value $=0.05$, calculations made on MATLAB).

Table 3. Summary of results for experiment A, including time of extraction (T), water tension of the soil sample TS, pore water before extraction, PW, extracted water EW, and percentage of recovery as the ratio of PW to EW.

\begin{tabular}{cccccc}
\hline Soil & T (min) & TS (kPa) & PW (g) & EW (g) & Recovery (\%) \\
\hline \multirow{4}{*}{ Arenosols } & 10 & 33 & - & - & - \\
& 25 & 33 & 0.69 & 0.4 & 58 \\
& 40 & 33 & 0.66 & 0.51 & 77 \\
& 50 & 33 & 0.71 & 0.67 & 94 \\
\hline \multirow{4}{*}{ Andosols } & 10 & 33 & 3.53 & 2.53 & 72 \\
& 45 & 33 & 3.42 & 2.87 & 84 \\
& 40 & 33 & 3.47 & 2.94 & 85 \\
& 50 & 33 & 3.37 & 3.05 & 91 \\
\hline
\end{tabular}

Built upon results from experiment A, Table 4 shows the results of Experiment B, related to the ability of the extraction setup to extract pore-water at different water tensions, starting from very dry $(1500 \mathrm{kPa})$ to very wet $(33 \mathrm{kPa})$ soil samples. In the case of Arenosols, it was possible to extract using CVE over $94 \%$ of pore water from soil samples with water content over $4.6 \%$ dry weight. However, there is a sharp decay on the recovery percentage for water contents in the range 3.57 to $4.6 \%$ dry weight, indicating the need for longer extraction times. It is worth noting that the decay on recovered water volume is not significant (Figure 3c), but in terms of recovery percentage (Figure 3d), the percentage for $1500 \mathrm{kPa}$ is below the $95 \%$ threshold. In the case of Andosols, recovery rates are rather constant, but less than $95 \%$ recommended to avoid fully fractionation.

One focus of the experiments was to explore the amount of extracted water at different retention energies. At low retention energy values, i.e., when soils are close to field capacity, the amount of extracted water from pores was high. However, the most relevant finding was that even at high retention energy values, i.e., when soil water contents were low ( $2.8 \%$ dry basis for Arenosols and $20 \%$ dry basis for Andosols), it was still possible to extract enough water from soil samples, even from soils with high sand content, matching the summer conditions at the site.

Results shown in Tables 3 and 4 shows a nonlinear relationship between recovery percentage and extraction time, as well as for recovery percentage and initial water content. This behaviour appears due to the strong non-linearity of the water content-retention energy relationship, so, for instance, large changes in extraction times lead to small changes in recovery percentage. Thus, for the case of soils derived from volcanic ashes, we observe that the most challenging situation occurs when soil sample are very dry, which, in turn, occurs during austral summer conditions. Regarding extraction times, we observe that extraction times over $50 \mathrm{~min}$ allows an acceptable level of recovery percentage, but for Andisols, extraction times should be greater than an hour. Experimental runs with extraction times of 60 min showed marginal improvements in recovery percentages for loamy soils, still below $95 \%$. Also, extraction runs showed large variability, so we recommend to increase the number of repetitions (more than 3 ) in the case of dry samples, regardless the soil type. Regarding the mass of soil samples, we chose $10 \mathrm{~g}$ after several tries. Larger soil mass (over $20 \mathrm{~g}$ ) where not included in this analysis, as they yield poor performance. Smaller samples, marginally improved recovery percentages, but the amount of recovered water was rather small to conduct isotopic analyses. Also, from an operational point of view, larger samples requires larger vessels, making the heating process less efficient. 
Table 4. Summary of results for experiment B, including time of extraction (T), water tension of the soil sample TS, pore water before extraction, $\mathrm{PW}$, extracted water EW, and percentage of recovery as the ratio $\mathrm{PW}$ to EW.

\begin{tabular}{cccccc}
\hline Soil & T (min) & TS (kPa) & PW (g) & EW (g) & Recovery (\%) \\
\hline \multirow{4}{*}{ Arenosols } & 50 & 33 & 0.69 & 0.65 & 94 \\
& 50 & 100 & 0.52 & 0.49 & 94 \\
& 50 & 300 & 0.51 & 0.51 & 100 \\
& 50 & 500 & 0.34 & 0.27 & 79 \\
Andosols & 50 & 1500 & 0.29 & 0.23 & 79 \\
& 50 & 33 & 3.44 & 2.95 & 86 \\
& 50 & 100 & 3.01 & 2.62 & 87 \\
& 50 & 300 & 2.73 & 2.36 & 86 \\
& 50 & 500 & 2.47 & 2.11 & 85 \\
& 1500 & 2.12 & 1.78 & 84 \\
\hline
\end{tabular}

(a)

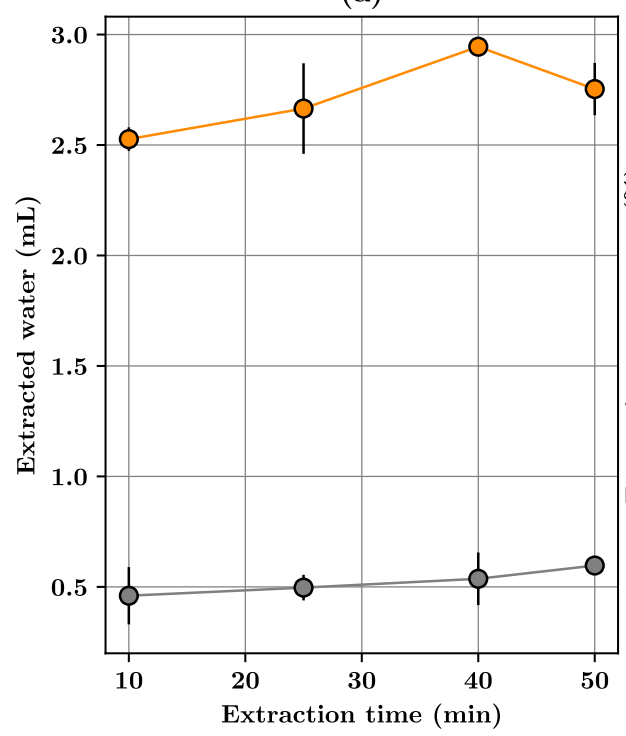

(c)

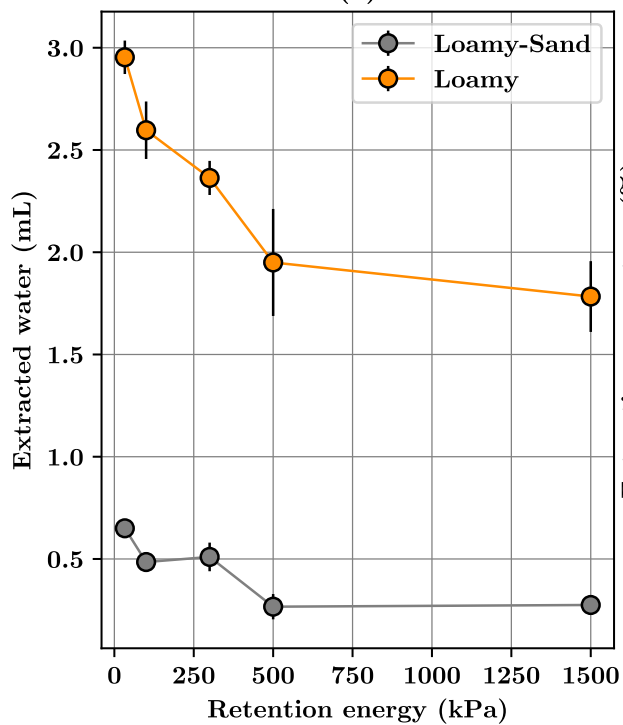

(b)

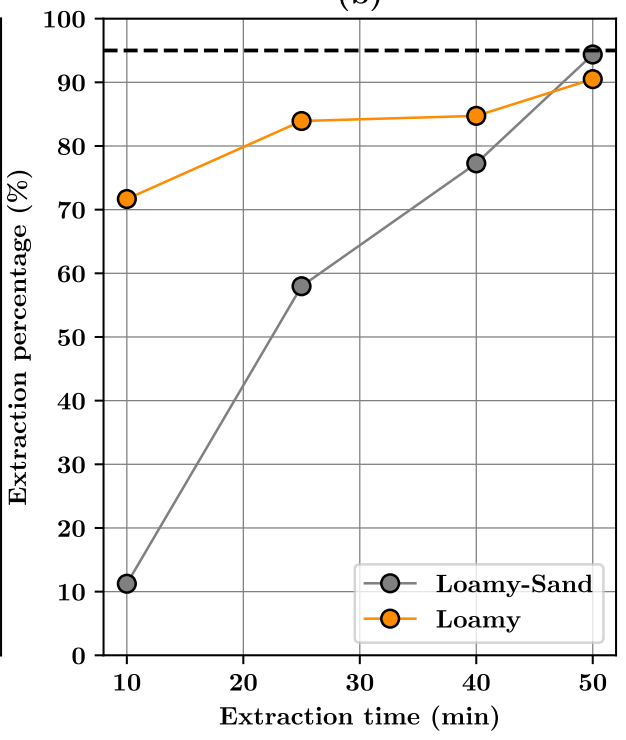

(d)

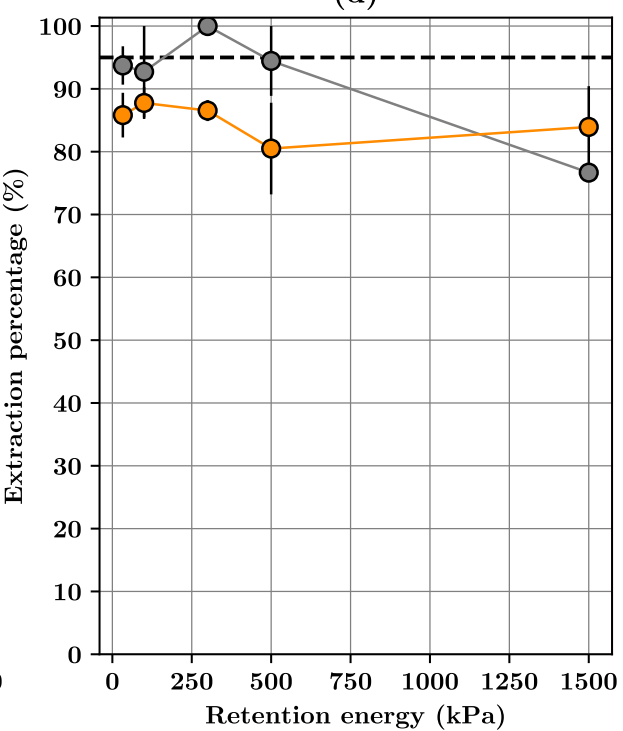

Figure 3. Experiment A: (a) Variation of extracted volumes of water after different extraction times (b) Variation of extraction percentages after different extraction times. For Experiment B (c) Variation of extracted volumes of water for different starting water contents (d) Variation of extraction percentages for different starting water contents. 
The reliability of the method relies on the assumption that there is no change in the isotopic ratios, ${ }^{18} \mathrm{O} /{ }^{16} \mathrm{O}$ or ${ }^{2} \mathrm{H} /{ }^{1} \mathrm{H}$, after extracting water from the soil sample. Indeed, results for Experiment $\mathrm{C}$ (Table 5, Figure 4) show that the procedure here presented maintained the isotopic ratio of the extracted water within a reliable range. First, the disagreement between laboratory measurements and the standard is low (less than the standard deviation informed by the laboratory) in a blind test. Second, in general terms, the deviation between the isotopic ratio of extracted water from loamy-sand and loamy soils and the standard was within the range $[-0.37 \%, 0.86 \%]$ for $\delta^{18} \mathrm{O}$ (mean difference of $0.03 \%$ ), and in the range [1.01\%, 9.1\%] for $\delta^{2} \mathrm{H}$ (mean difference of $4.68 \%$ ). However, there were differences among samples as standard deviation was $0.49 \%$ for $\delta^{18} \mathrm{O}$ and $3.45 \%$ for $\delta^{2} \mathrm{H}$. The isotopic ratio from loamy-sand samples showed a smaller deviation compared to the standard than loamy soils as the clay and silt content was higher. Indeed, a single loamy-soil sample led to a large difference for $\delta^{2} \mathrm{H}$, likely due to an operational problem on that single run.

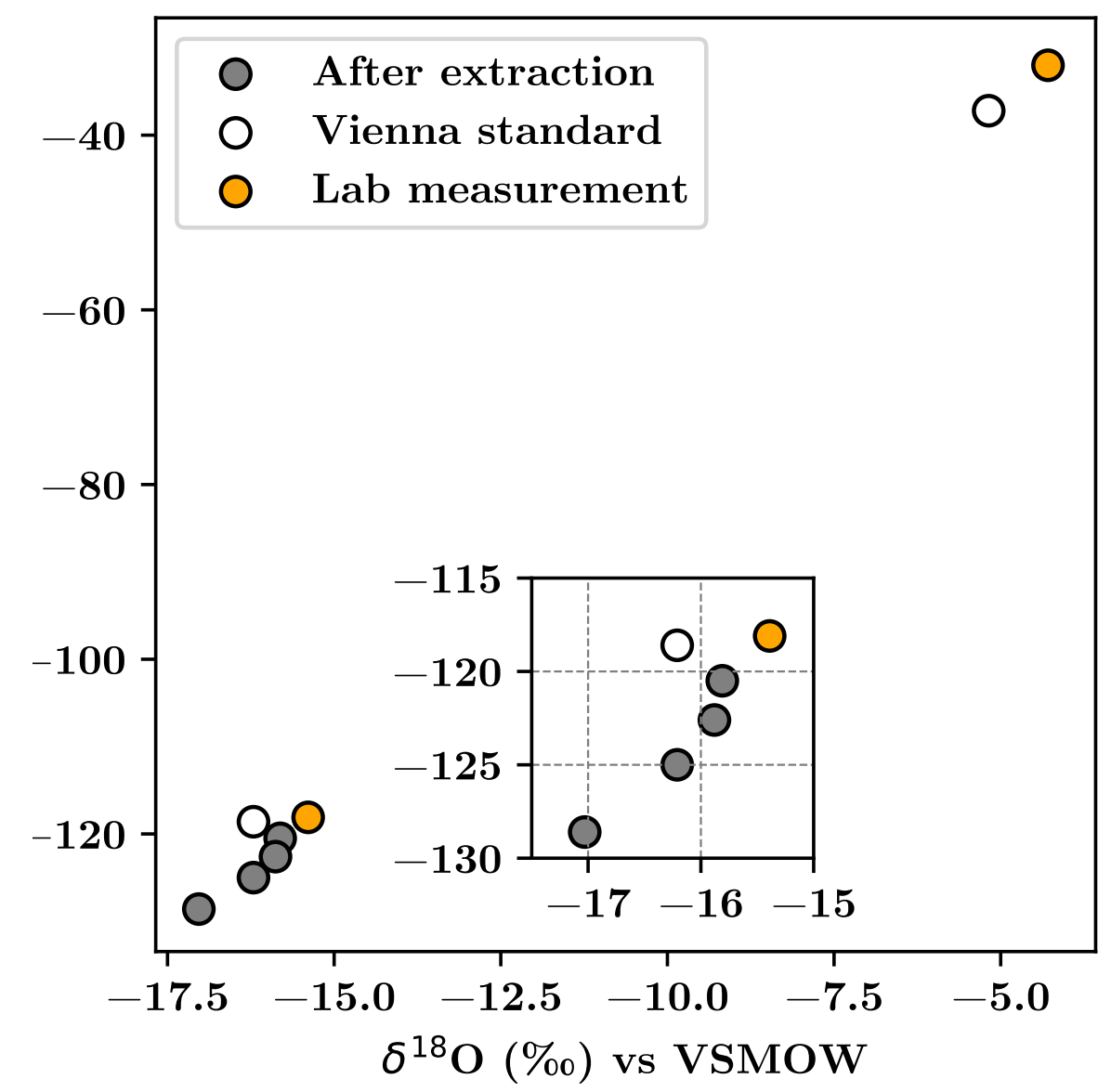

Figure 4. Comparison of isotopic signatures for laboratory measurements and for extracted water.

Table 5. Summary of results for experiment C. $\delta^{18} \mathrm{O}$ and $\delta^{2} \mathrm{H}$ are relative to the Vienna Standard Mean Ocean Water (VSMOW).

\begin{tabular}{ccc}
\hline Soil & $\boldsymbol{\delta}^{\mathbf{1 8}} \mathbf{O} \mathbf{( \% )}$ & $\delta^{\mathbf{2}} \mathbf{H} \mathbf{( \% )}$ \\
\hline Arenosol & -15.81 & -120.53 \\
Arenosol & -16.21 & -125.02 \\
Andosol & -17.03 & -128.56 \\
Andosol & -15.88 & -122.61 \\
Labelled & -16.20 & -119.50 \\
\hline
\end{tabular}




\section{Discussion}

We would like to draw attention to conclusions from Orlowski et al. [22] and Orlowski et al. [23] which stated that soil heterogeneity and sample handling could lead to significant differences in the isotopic ratio before and after extraction, as well as the precision of the laboratory equipment as compared to the isotopic composition standards. As noted by Orlowski et al. [18] and Orlowski et al. [22], extracting water from dried and re-hydrated samples could lead to changes on isotopic composition, especially in soils with high clay contentas Andosols.

In a large inter-comparison exercise among 16 laboratories, Orlowski et al. [22] highlights the differences in recovery percentage and changes in isotopic composition for two soil, clay-dominated and sand-dominated, for two different water contents $(8 \%$ and $20 \%$. They report differences between spiked and extracted water for $\delta^{2} \mathrm{H}$ of around $20 \%$ ), while our experiments showed difference of $4.68 \%$ ). For $\delta^{18} \mathrm{O}$, the same authors report differFences around $4 \%$ ), while our experiments showed a difference of $0.03 \%$ ). Overall, our extraction procedure showed smaller differences of isotopic ratios before and after extraction runs than those reported in inter-comparison exercises [22] and other comparison studies $[15,20]$. It is worth noting that, large differences among CVE devices and procedures, impede to advise for specific conditions or comparision among absolute values [15,20,22]. However, if the same procedure is followed for all runs, those differences could be considered as systematic errors that allow to compare values.

To address soil heterogeneity and re-hydration, large samples (over $1 \mathrm{~kg}$ ) were prepared before extraction. Additionally, we tested 5 levels of soil water content, in order to include strong drying conditions at the site.

Regarding extraction time, as noted by Orlowski et al. [23], short extraction times could lead to changes on the isotopic ratio of recovered water if the evaporation process is not complete. Also, Orlowski et al. [23] signals that CVE produces isotopic "artifacts" from spiked water experiments. Our results show that, when soil samples have low water content, specially for Andosols with high clay proportion, it appears necessary to increase extraction times up to $90 \mathrm{~min}$. However, Newberry et al. [21] indicates that those artifacts are irrelevant for field data when the isotopic composition is unknown, that could be the case in our study due to the strong heterogeneity of soils in the site from where samples were taken. Also, conclusions in Newberry et al. [21] are equivalent to state that the magnitude of the differences on isotopic composition before and after CVE is smaller than the uncertainty of actual isotopic composition in the field. To address this issue, we run CVE for several soil samples from the field to obtain the isotopic ratio of pore water. Our results revealed that a strong evaporation process happened during summer, as there was a significant change on the slope compared to the local meteoric line proposed by Arumí et al. [30]. Thus, the procedure was able to reproduce conditions of changes in the isotopic composition due to water evaporation from soil [5-9].

Regarding the differences between clay-dominated and sand-dominated soils, Orlowski et al. [18] tested 6 extraction times $(15,30,45,60,120$ and $180 \mathrm{~min})$ as clay soils can show problems due to pore water that could be weakly bounded to the soil. However, Orlowski et al. [18] showed that there are no significant differences on the stable isotopic ratio due to extraction time. Based on Orlowski et al. [18], we set the extraction time limit to $50 \mathrm{~min}$. Our results showed that $50 \mathrm{~min}$ suffice to recover more than $0.1 \mathrm{~mL}$ at the most restrictive conditions, i.e., low water content in the soil sample corresponding to very dry site conditions. Extraction times to recover more than $90 \%$ of water on the soil sample water were in agreement with previous studies $[15,17,19,20]$.

Drift on the isotopic ratio after cryogenic extraction was noted by Orlowski et al. [23] and Orlowski et al. [22], as they concluded that extraction methods where a strong phase change of water takes place such as microwave, direct vapor equilibration, and cryogenic extraction, exhibited the largest isotopic discrepancies compared to the water samples with known isotopic ratios. Moreover, Orlowski et al. [23], Newberry et al. [31] and Orlowski et al. [22] explained differences of the isotopic ratio $\delta^{2} \mathrm{H} / \delta^{18} \mathrm{O}$ on the grounds of specific features of the experimental setup or the effects at molecular 
level during phase changes that the water molecule before analysis. Indeed, literature indicates that differences are more likely to appear for clayey and loamy soils, both of which were tested in this study. Another potential source of isotopic drift is the organic content of extracted water from soil samples containing higher percentages of organic matter, as Fractionation effects due to soil type increases with clay and organic matter content [20]. However, the effect fractionation from organic-rich soils is still an open question [22,23]. In this research, we did not perform any correction, as the presence on high organic content in Andodols occurs at the lowlands, due to accumulation, but our samples were taken from sites that present low content of organic matter in upper catchments.

Thoma et al. [20] compared pore water samplers, such as suction cups deployed in the field against cryogenic extraction in the laboratory. They found no significant differences under laboratory conditions (dried and re-hydrated), but did find differences when comparing water extracted from field. Indeed, these authors explain such differences in terms of the capacity of both methods to sample pore water from larger pores, usually linked to recent inputs, and finer pores containing older water. Thus, cryogenic extraction yields water samples that are a mix of recent and olde water, as it extracts pore water in a wide range of retention energies.

Despite their socio-ecological importance, there is little research on the hillslope hydrology of Andosols. Indeed, a deeper understanding of hydrological processes in upper catchments could support policy making related to water conservation and climate change. Even though this research focus in a very fundamental question, it is worth noting that the Supreme Court of Chile (Case 1239: 2018, 7 August 2019, where the Court ruled as a mandatory guidance to consider scientific knowledge under Law 20.473) underlined that scientific information provided by experts must be taken into account before adopting judicial decisions. Thus, this research could provide relevant information about volcanic soils.

\section{Conclusions}

This research presented a simple cryogenic extraction device to extract water from soils derived from volcanic ash Andosols and Arenosols from an upper catchment within the Itata River Basin. Our first important finding is that for Andosols and Arenosols it was possible to recover enough water volume for isotopic analysis, recovering over $90 \%$ of water initially in the sample after $50 \mathrm{~min}$ starting from soil samples close to field capacity (Experiment A). Secondly, we showed that it is possible to recover water from clayey soils even at very low water content, which is an important conclusion (Experiment B) regarding the ability of the procedure to obtain water during wet and very dry conditions. However, as expected, there were small changes on the isotopic ratio of water due to operational issues, the changes on water phase during the extraction, and clay content (Experiment C). In the case of very dry samples of clay dominated soils, we advise to increase the extraction time for dry Andosols up to $90 \mathrm{~min}$. Also, when a new CVE device is setup, it is advisable to conduct preliminary runs, as described here, to ensure extraction volume and set extraction times.

As described on the literature, Cryogenic Vacuum Extraction is suitable to extract pore water from different soil types. However, special care should be taken when setting up a cryogenic extraction line with respect to the differences on soil composition, most importantly clay content, and water content of soils samples as both variables define the extraction time and extracted volume, as it is the case of volcanic soils.

Despite Andean upper catchments provide significant ecosystem services for downstream water uses, there are few studies regarding the role of water storage and release as a resilience mechanism against impacts of climate change and variability. This research shows that cryogenic vacuum extraction is a useful method to carry out larger isotopic research to understand hydrological processes in volcanic soils in Central Chile.

Author Contributions: D.R. and W.V.-C. conceived and designed the experiments; K.G. performed the experiments; L.F. performed the isotopic analyses; M.Z.-B., A.G.-F. and A.Á. contributed to re-organize the initial draft and some data analysis. All authors contributed to write the paper. 
Funding: This research received funding from grants FONDECYT 1160656 and CONICYT/FONDAP/15130015.

Acknowledgments: We acknowledge the financial support from the Fondo Nacional de Desarrollo Científico y Tecnológico trough grant FONDECYT 1160656, that covered analyses, travels and material, as well publication costs. D Rivera also thanks financial support from CONICYT/FONDAP/15130015. L Farías thanks support from CONICYT/FONDAP 15110009.

Conflicts of Interest: The authors declare no conflict of interest.

\section{References}

1. Kendall, C.; McDonnell, J.J. Isotope Tracers in Catchment Hydrology; Elsevier: Amsterdam, The Netherlands, 2012.

2. Gusyev, M.A.; Toews, M.; Morgenstern, U.; Stewart, M.; White, P.; Daughney, C.; Hadfield, J. Calibration of a transient transport model to tritium data in streams and simulation of groundwater ages in the western Lake Taupo catchment, New Zealand. Hydrol. Earth Syst. Sci. 2013, 17, 1217-1227. [CrossRef]

3. Birkel, C.; Soulsby, C. Advancing tracer-aided rainfall-runoff modelling: A review of progress, problems and unrealised potential. Hydrol. Process. 2015, 29, 5227-5240. [CrossRef]

4. Yang, K.; Han, G.; Liu, M.; Li, X.; Liu, J.; Zhang, Q. Spatial and Seasonal Variation of O and H Isotopes in the Jiulong River, Southeast China. Water 2018, 10, 1677. [CrossRef]

5. Garvelmann, J.; Külls, C.; Weiler, M. A porewater-based stable isotope approach for the investigation of subsurface hydrological processes. Hydrol. Earth Syst. Sci. 2012, 16, 631-640. [CrossRef]

6. Sprenger, M.; Volkmann, T.H.; Blume, T.; Weiler, M. Estimating flow and transport parameters in the unsaturated zone with pore water stable isotopes. Hydrol. Earth Syst. Sci. 2015, 19, 2617-2635. [CrossRef]

7. Windhorst, D.; Kraft, P.; Timbe, E.; Frede, H.G.; Breuer, L. Stable water isotope tracing through hydrological models for disentangling runoff generation processes at the hillslope scale. Hydrol. Earth Syst. Sci. 2014, 18, 4113-4127. [CrossRef]

8. Orlowski, N.; Lauer, F.; Kraft, P.; Frede, H.G.; Breuer, L. Linking spatial patterns of groundwater table dynamics and streamflow generation processes in a small developed catchment. Water 2014, 6, 3085-3117. [CrossRef]

9. Orlowski, N.; Kraft, P.; Pferdmenges, J.; Breuer, L. Exploring water cycle dynamics by sampling multiple stable water isotope pools in a developed landscape in Germany. Hydrol. Earth Syst. Sci. 2016, 20, 3873-3894. [CrossRef]

10. Evaristo, J.; McDonnell, J.J.; Scholl, M.A.; Bruijnzeel, L.A.; Chun, K.P. Insights into plant water uptake from xylem-water isotope measurements in two tropical catchments with contrasting moisture conditions. Hydrol. Process. 2016, 30, 3210-3227. [CrossRef]

11. Evaristo, J.; McDonnell, J.J. Prevalence and magnitude of groundwater use by vegetation: A global stable isotope meta-analysis. Sci. Rep. 2017, 7, 44110. [CrossRef]

12. Sprenger, M.; Tetzlaff, D.; Soulsby, C. Stable isotopes reveal evaporation dynamics at the soil-plant-atmosphere interface of the critical zone. Hydrol. Earth Syst. Sci. 2017, 21, 3839-3858. [CrossRef]

13. Hervé-Fernández, P.; Oyarzún, C.; Brumbt, C.; Huygens, D.; Bodé, S.; Verhoest, N.; Boeckx, P. Assessing the 'two water worlds' hypothesis and water sources for native and exotic evergreen species in south-central Chile. Hydrol. Process. 2016, 30, 4227-4241. [CrossRef]

14. Di Bonito, M.; Breward, N.; Crout, N.; Smith, B.; Young, S. Overview of selected soil pore water extraction methods for the determination of potentially toxic elements in contaminated soils: Operational and technical aspects. In Environmental Geochemistry; Elsevier: Amsterdam, The Netherlands, 2008; pp. 213-249.

15. Millar, C.; Pratt, D.; Schneider, D.J.; McDonnell, J.J. A comparison of extraction systems for plant water stable isotope analysis. Rapid Commun. Mass Spectrom. 2018, 32, 1031-1044. [CrossRef] [PubMed]

16. Orlowski, N.; Pratt, D.L.; McDonnell, J.J. Intercomparison of soil pore water extraction methods for stable isotope analysis. Hydrol. Process. 2016, 30, 3434-3449. [CrossRef]

17. Koeniger, P.; Marshall, J.D.; Link, T.; Mulch, A. An inexpensive, fast, and reliable method for vacuum extraction of soil and plant water for stable isotope analyses by mass spectrometry. Rapid Commun. Mass Spectrom. 2011, 25, 3041-3048. [CrossRef] [PubMed]

18. Orlowski, N.; Frede, H.G.; Brüggemann, N.; Breuer, L. Validation and application of a cryogenic vacuum extraction system for soil and plant water extraction for isotope analysis. J. Sens. Sens. Syst. 2013, 2, 179-193. [CrossRef] 
19. West, A.G.; Patrickson, S.J.; Ehleringer, J.R. Water extraction times for plant and soil materials used in stable isotope analysis. Rapid Commun. Mass Spectrom. 2006, 20, 1317-1321. [CrossRef]

20. Thoma, M.; Frentress, J.; Tagliavini, M.; Scandellari, F. Comparison of pore water samplers and cryogenic distillation under laboratory and field conditions for soil water stable isotope analysis. Isot. Environ. Health Stud. 2018, 54, 403-417. [CrossRef]

21. Newberry, S.; Nelson, D.; Kahmen, A. Cryogenic vacuum artifacts do not affect plant water-uptake studies using stable isotope analysis. Ecohydrology 2017, 10, e1892. [CrossRef]

22. Orlowski, N.; Breuer, L.; Angeli, N.; Boeckx, P.; Brumbt, C.; Cook, C.S.; Dubbert, M.; Dyckmans, J.; Gallagher, B.; Gralher, B.; et al. Inter-laboratory comparison of cryogenic water extraction systems for stable isotope analysis of soil water. Hydrol. Earth Syst. Sci. 2018, 22, 3619-3637. [CrossRef]

23. Orlowski, N.; Breuer, L.; McDonnell, J.J. Critical issues with cryogenic extraction of soil water for stable isotope analysis. Ecohydrology 2016, 9, 1-5. [CrossRef]

24. Aguilera, M.; de la Luz Mora, M.; Borie, G.; Peirano, P.; Zunino, H. Balance and distribution of sulphur in volcanic ash-derived soils in Chile. Soil Biol. Biochem. 2002, 34, 1355-1361. [CrossRef]

25. Langohr, R. The volcanic ash soils of the Central Valley of central Chile. Pédologie 1971, 3, 259-293.

26. Rivera, D.; Sandoval, M.; Godoy, A. Exploring soil databases: A self-organizing map approach. Soil Use Manag. 2015, 31, 121-131. [CrossRef]

27. Dörner, J.; Huertas, J.; Cuevas, J.G.; Leiva, C.; Paulino, L.; Arumí, J.L. Water content dynamics in a volcanic ash soil slope in southern Chile. J. Plant Nutr. Soil Sci. 2015, 178, 693-702. [CrossRef]

28. Fleige, H.; Beck-Broichsitter, S.; Dörner, J.; Goebel, M.O.; Bachmann, J.; Horn, R. Land use and soil development in southern Chile: Effects on physical properties. J. Soil Sci. Plant Nutr. 2016, 16, 818-831. [CrossRef]

29. Sandoval, M.; Dörner, J.; Seguel, O.; Cuevas, J.; Rivera, D. Métodos de análisis físicos de suelos; Publicaciones del Departamento de Suelos y Recursos Naturales: Chillán, Chile, 2012.

30. Arumí, J.L.; Oyarzún, R.; Munoz, E.; Rivera, D.; Aguirre, E. Characterization of Two Spring Clusters at the Diguillin River, Chile. Tecnol. Cienc. Agua 2014, 5, 151-158.

31. Newberry, S.L.; Prechsl, U.E.; Pace, M.; Kahmen, A. Tightly bound soil water introduces isotopic memory effects on mobile and extractable soil water pools. Isot. Environ. Health Stud. 2017, 53, 368-381. [CrossRef]

(C) 2019 by the authors. Licensee MDPI, Basel, Switzerland. This article is an open access article distributed under the terms and conditions of the Creative Commons Attribution (CC BY) license (http:/ / creativecommons.org/licenses/by/4.0/). 